\title{
Serological evaluation of herpes simplex virus type \\ Original \\ 1 and type 2 infections in pregnancy
} article

\section{Department of \\ Virology and Vaccine \\ Research, University \\ of Tampere Medical \\ School, Tampere, \\ Finland \\ M Arvaja \\ T Vesikari}

\section{Department of}

Infectious Disease

Epidemiology,

National Public Health

Institute, Helsinki,

Finland

M Lehtinen

National Public Health

Institute, Oulu,

Finland

P Koskela

\section{Department of}

Virology, University of Helsinki, Helsinki,

Finland

M Lappalainen

\section{Department of}

Obstetrics and

Gynaecology,

University of Helsinki,

Helsinki, Finland

J Paavonen

Correspondence to:

Professor Timo Vesikari,

Department of Virology,

University of Tampere,

Medical School, POB 607,

FIN-33101 Tampere,

Finland.

Accepted for publication

26 February 1999

\author{
M Arvaja, M Lehtinen, P Koskela, M Lappalainen, J Paavonen, T Vesikari
}

Objective: Serological evaluation of herpes simplex virus infections during pregnancy.

Methods: 2991 serum samples were obtained during 1st, 2nd, and 3rd trimester from 997 pregnant women. Baculovirus expressed glycoproteins gG1 (HSV-1) and gG2 (HSV-2) were used as antigens in ELISA for HSV-1 and HSV-2 IgG and IgA antibodies.

Results: The prevalence of HSV-1 gGl antibodies was $70 \%$ and that of HSV-2 gG2 antibodies $16 \%$. Among susceptible women we found five $(0.6 \%)$ cases with serological evidence of primary HSV-2 infection during pregnancy. Evidence of active HSV-1 infection was found in nine $(0.9 \%)$ cases. Decline of HSV-2 gG2 IgG antibody levels during pregnancy was pronounced compared with HSV-1 gG1 IgG antibody levels $(\mathrm{p}<0.01)$; also the proportion of seroreversions was considerably higher among HSV-2 seropositives (25\%) than among HSV-1 seropositives (3\%) $(\mathrm{p}<0.001)$.

Conclusions: HSV-2 gG2 IgG antibodies were readily distinguished from HSV-1 gG1 IgG antibodies by the glycoprotein gG ELISAs. Serological assays for gG2 antibodies should guard against the decline of specific antibodies during pregnancy.

(Sex Transm Inf 1999;75:168-171)

Keywords: glycoprotein gG; herpes simplex virus; pregnancy; neonatal herpes

\section{Introduction}

Genital herpes simplex virus (HSV) infection in pregnant women is associated with a risk of viral transmission to the infant at delivery, but identification of the risk pregnancies remains enigmatic. ${ }^{1}$ While reactivation of maternal $\mathrm{HSV}$ infection and primary infection during pregnancy are common, the risk of associated neonatal HSV infection is 10 times higher for offspring of women with primary infection near labour and with no time to develop an adequate immune response. ${ }^{2-4}$ Primary HSV type 2 (HSV-2) infections, particularly in the last trimester of pregnancy, are associated with high morbidity and mortality of the infant. ${ }^{56}$ Clinical examination is likely to miss many cases of genital herpes ${ }^{7}$ and antepartum cultures may not accurately predict viral shedding at the time of delivery. ${ }^{8}$ Serological evaluation of HSV-2 infections during pregnancy might provide a way to identify risk deliveries.

Standard serological methods do not distinguish HSV-2 antibodies from HSV-1 antibodies. ${ }^{9}$ However, determination of type specific antibodies to HSV-2 glycoprotein G2 (gG2) has made it possible to establish a specific diagnosis of past or current HSV-2 infections. ${ }^{10-13}$ Using gene technology large quantities of gG2 and gGl can be produced ${ }^{14}$ and applied for screening of HSV-2 antibodies. We have used the gG2 and gGl antigens in an ELISA test to study the prevalence of HSV-2 and HSV-1 antibodies in pregnant women and to screen for HSV-2 and HSV-1 infections during pregnancy.

\section{Methods}

Sequential serum samples of pregnant women, collected in each trimester from 16733 pregnant women in the Helsinki area from
January 1988 to May 1989, were available from a population based screening trial for congenital infections with a participation rate of $90.2 \% .^{16}$ For the present study three serum samples, one from each trimester of 997 randomly selected women (altogether 2991 sera) were retrieved from $-25^{\circ} \mathrm{C}$. The mean age of the women was 30 years and their age distribution is shown in table 1 .

Production of the HSV-1 and HSV-2 specific gG1 and gG2 by recombinant baculoviruses AcDSMgG-1 and AcDSMgG-2 has been described elsewhere. ${ }^{14}{ }^{17}$ The recombinants carry $871 \mathrm{bp}$ and $3779 \mathrm{bp}$ fragments of HSV-1 gG1 and HSV-2 gG2 genes, respectively, and express in Sf9 cells 37 to $42 \mathrm{kDa}$ (gG1) and $118 \mathrm{kDa}$ (gG-2) proteins to cell culture supernatants. The supernatants containing gG1 and gG2, a generous gift from Dr Philip E Pellet (CDC, Atlanta, GA, USA), were centrifuged (500 $g \times 10$ minutes), and stored in aliquots at $-70^{\circ} \mathrm{C}$.

IgG and IgA antibodies to HSV-1 gG1 and HSV-2 gG2 were determined by ELISA as follows. The antigens were diluted in phosphate buffered saline (PBS) (pH 7.2) at a final concentration of $5 \mu \mathrm{g} / \mathrm{ml}$ and used for coating

Table 1 Age related prevalence of $\mathrm{HSV}-2$ and $\mathrm{HSV}-\mathrm{l}$ specific IgG antibodies in pregnant women during the first trimester

\begin{tabular}{llll}
\hline & & \multicolumn{2}{l}{ No (\%) seropositive } \\
\cline { 3 - 4 } Age group & $\begin{array}{l}\text { No of } \\
\text { subjects }\end{array}$ & HSV-2 gG2 & HSV-1 gG1 \\
\hline-20 & 36 & $5(13.9)$ & $26(72.2)$ \\
$21-25$ & 181 & $29(16.0)$ & $132(72.9)$ \\
$26-30$ & 344 & $60(17.4)$ & $323(67.4)$ \\
$31-35$ & 297 & $46(15.5)$ & $211(71.0)$ \\
$36-40$ & 121 & $13(10.7)$ & $82(67.8)$ \\
$41-$ & 18 & $4(22.2)$ & $15(83.3)$ \\
Total & 997 & $157(15.7)$ & $689(70.0)$ \\
\hline
\end{tabular}




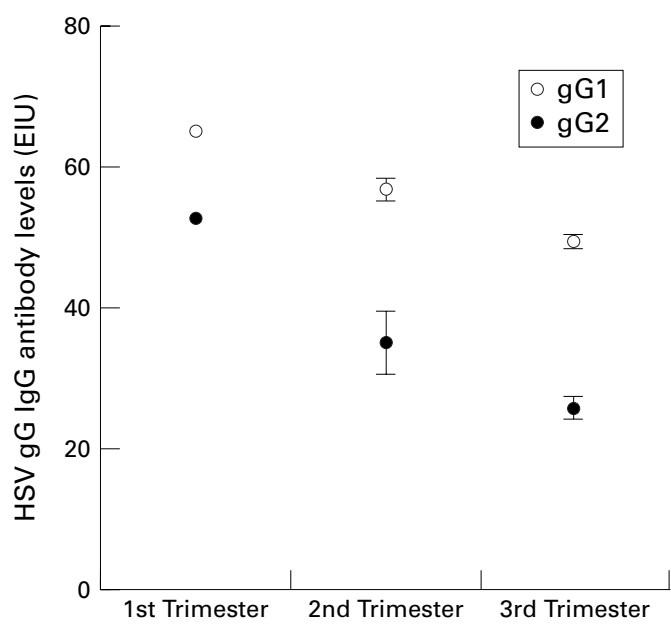

Figure 1 Changes over time of HSV-1 gG1 and HSV-2 gG2 IgG antibody levels in initially seropositive pregnant women at the second and the third trimester. Mean antibody levels at each of the three trimesters plus or minus 2 SEM decline at the second and third trimester are shown for both $g G 1$ and $g G 2 \operatorname{IgG}$ class antibodies.

of microtitre plates (Macrosorb F-plates, NUNC a/s, Copenhagen, Denmark) overnight at $4^{\circ} \mathrm{C}$. The next morning the plates were washed with a washing buffer (PBS containing $0.5 \%$ Tween 20 ) and saturated for 1 hour at $37^{\circ} \mathrm{C}$ with $10 \%$ fetal calf serum (FCS) in PBS. Prediluted serum samples were added into duplicate wells (final dilution 1/100) and incubated for 1 hour at $37^{\circ} \mathrm{C}$. After the incubation the serum dilutions were recollected for further use. After washing, alkaline phosphatase conjugated antihuman IgG (Dakopatts a/s, Glostrup, Denmark) diluted 1:500 was added; the plates were incubated for 1 hour at $37^{\circ} \mathrm{C}$ and washed. Paranitrophenyl phosphate substrate (Sigma, St Louis, MO, USA) was added to the wells for 30 minutes after which the optical densities (ODs) were photometrically read at $405 \mathrm{~nm}$. For the detection of $\operatorname{IgA}$ antibodies, the same plates were washed three times both with diethanolamine buffer (Orion Diagnostica, Espoo, Finland) and PBS, after which the preserved serum samples were added to the same individual plate wells (final dilution $1 / 80$ ) and incubated at $37^{\circ} \mathrm{C}$ for 1 hour. The plates were washed, and $\operatorname{IgA}$ peroxidase conjugate (Dakopatts) diluted 1:500 was added for 1 hour incubation at $37^{\circ} \mathrm{C}$. After washing the substrate solution, o-phenylenediamine (Sigma), was added for 15 minutes. After stopping the reaction with $1 \mathrm{M} \mathrm{H}_{2} \mathrm{SO}_{4}$ the ODs were read at $492 \mathrm{~nm}$. Mean ODs of the positive reference sera were $0.683,0.420,0.447,0.417$ for HSV-1 and HSV-2 IgG and IgA antibodies, respectively. Intra-assay variation between duplicates of the same samples was low, with mean coefficient variation of $4.9 \%, 5.2 \%$, $8.1 \%$, and $8.4 \%$ for HSV-1 and HSV-2 IgG and $\operatorname{IgA}$ antibodies, respectively.

ELISA of HSV IgG antibodies using HSV-1 infected cell lysate antigen was as described. ${ }^{18}$

To avoid interassay variation antibody reactivity was expressed as background corrected percentage - that is, enzyme immuno units (EIU). The EIU is obtained by subtracting the OD of a known negative reference serum from the OD of a given serum sample, dividing it by the OD of a known reference positive serum minus OD of the negative reference serum and multiplying the result by $100 .^{19}$ Cut off levels for HSV-1 and HSV-2 seropositivity were calculated using sera from 45 one year old children as a reference material. All were negative for HSV-2 IgG antibodies, and the cut off level for the presence of HSV-2 IgG antibodies was calculated as a mean plus three standard deviations (SD). For HSV-1 IgG antibodies outliers (HSV-1 seropositive children) were excluded by iterating calculation of the cut off level (mean $+3 \mathrm{SD}$ ) until no outliers were left. ${ }^{20}$ Thereafter the cut off level for the presence of HSV-1 IgG antibodies was calculated from the remaining sera as a mean $+3 \mathrm{SD}$. As a result, the cut off level for HSV-2 was 28 EIU and for HSV-1 21 EIU. A seroconversion was defined as a rise equal to or higher than $20 \mathrm{EIUs},{ }^{19} 2122$ within the three consecutive samples the overall rise had to be equal to or higher than the cut off level.

Statistical significance of changes in the antibody levels between different trimesters, and differences in the frequencies of seroconversions and seroreversions were tested with paired $t$ test and $\chi^{2}$ test using the BMDP statistical software (BMDP Inc, Cork, Ireland).

\section{Results}

In the 997 first trimester serum samples the prevalence of IgG antibodies to HSV-2 was $16 \%$, and to HSV-1 $70 \%$ (table 1). Of the 997 mothers, 280 (28\%) were seronegative for both HSV-1 and HSV-2, $560(56 \%)$ had HSV-1 antibodies only, and 19 (2\%) had HSV-2 antibodies only. The prevalence of HSV-2 IgG antibodies was $14 \%$ in the youngest age group, $17 \%$ in the age group $26-30$ years, and $22 \%$ in the age group over 40 years. Altogether, there was little variation in the prevalence of HSV-1 antibodies between the different age groups.

In the first trimester the range of $\mathrm{HSV}-2 \mathrm{IgG}$ antibody levels was from 0 to 388 EIU (median among the HSV-2 seropositives was 42 EIU) and that of HSV-1 IgG antibody levels from zero to 248 EIU (median among HSV-1 seropositives was 54 EIU). All the second and third trimester serum samples were also analysed. Among the seropositives a general decline of IgG antibody levels was observed during the pregnancy both for HSV-2 and HSV-1 (fig 1). As a result of this decline some seropositive cases reverted to seronegative. The reversion to seronegative occurred in 24 cases (3\%) with HSV-1 antibodies and in 40 cases (25\%) with HSV-2 antibodies. For HSV-2 both the absolute decrease of antibody levels and proportion of seroreversions were more pronounced than for HSV-1 ( $p<0.01$ and $\mathrm{p}<0.001$, respectively).

Of the 840 individuals who were seronegative for HSV-2 in the first trimester five $(0.6 \%)$ seroconverted during pregnancy (fig $2 \mathrm{~A}$ ). In four of the five individuals the HSV-2 antibody response occurred between second and third trimester, and in one individual between first and second trimester. Three women with HSV-2 seroconversion were initially negative for antibodies to HSV-1 gG1 and the cross reactive HSV-1 infected cell lysate antigen. The 

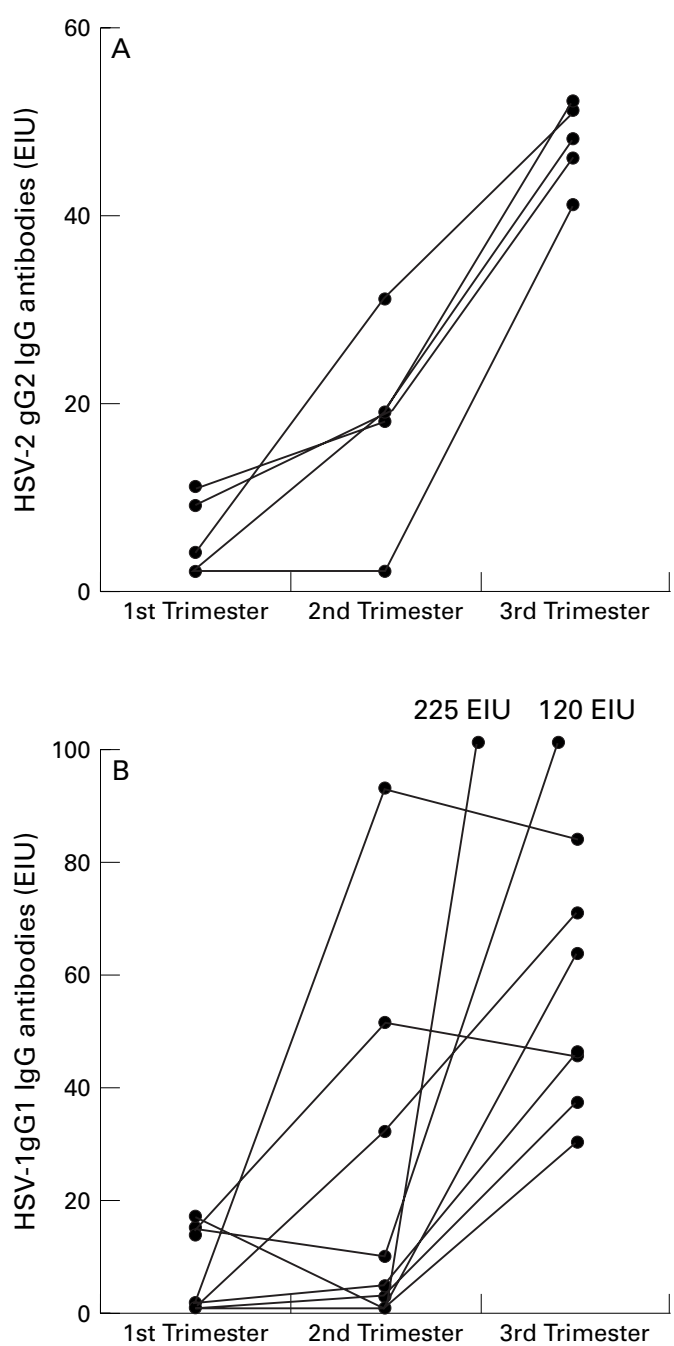

Figure 2 (A) HSV-2 gG2 IgG antibody responses in five women with primary $H S V-2$ infection during pregnancy. (B) HSV-1 gG1 IgG antibody responses in nine women (B) HSV-1 gG1 IgG antibody responses in nine women
with a significant increase in the specific antibody levels during pregnancy.

HSV-1 gG1 antibody levels did not change with HSV-2 seroconversion. IgA antibodies to HSV-2 gG2 were present in all five seroconverters after IgG seroconversion. In three cases IgA antibodies were detectable already in the previous sample, and one case showed an increase in HSV-2 gG2 IgA antibody level before the IgG seroconversion. In the remaining two individuals the IgA antibody responses were concomitant with the HSV-2 IgG seroconversion.

Of the 299 women who were negative for HSV-1 gG1 antibodies in the first trimester, nine $(3 \%)$ seroconverted (fig $2 \mathrm{~B})$. However, only one of the nine cases was initially seronegative for HSV as measured by an HSV-1 infected cell lysate ELISA. In three of these individuals a moderate albeit insignificant increase of the HSV-2 gG2 IgG antibody levels was observed concomitantly with the HSV-1 gG1 seroconversion. IgA antibodies to HSV-1 gG1 and HSV-2 gG2 were observed in three individuals already in the first trimester. In three other individuals the IgA antibody responses were comparable with the $\mathrm{IgG}$ responses.

\section{Discussion}

The prevalence of HSV-2 (16\%) antibodies in Finnish women, as measured by gG2 ELISA, is comparable with that in many other countries. ${ }^{23}$ Most HSV-2 seropositive women had acquired HSV-2 infection by the age of 25 years. This is in line with what has been reported for similar American and Swedish populations of pregnant women. ${ }^{24-26}$ The prevalence of HSV-2 antibodies increased by $2.1 \%$ within the first 5 years and by $1.4 \%$ within the next 5 years. Thus, the crude incidence of HSV-2 infections in Finnish women between ages 21 and 30 years was $0.3-$ $0.4 \%$. In non-pregnant populations primary HSV-2 infections have been suggested to occur at a constant rate throughout the years of sexual activity ${ }^{132728}$; in our study this could not be evaluated owing to decline of antibody levels over time.

The observed frequency of HSV-2 seroconversions during pregnancy in this study was $0.6 \%$, which is line with other studies. ${ }^{425}$ Of the pregnant women who were initially seronegative for HSV-2, $28 \%$ had no HSV-1 gGl antibodies either. Both HSV-1 and HSV-2 antibodies have been reported to protect from acquisition of heterologous infection among women. ${ }^{429}$ In our study the frequency of HSV-2 seroconversions was $0.4 \%$ among pregnant women with serological evidence of earlier HSV-1 infection, compared with $1.1 \%$ among those without HSV-1 antibodies. Duration of pregnancy may also predispose to primary HSV infection. ${ }^{4}$ This was suggested for HSV-2 by the excess of seroconversions (four against one) in late pregnancy, but not for HSV-1 (four and five seroconversions in early and late pregnancy, respectively).

The HSV-2 gene for gG2 contains a long unique DNA sequence with no counterparts in the HSV-1 genome. ${ }^{30}$ It seems that human antibody responses to the unique epitopes of the gG2 are dominant ${ }^{912} 1415$ but variable. ${ }^{31}$ The former explains the lack of cross reactivity of HSV-2 gG2 IgG antibodies with the gGl antigen, while the latter is associated with the transience of HSV-2 gG2 IgG antibody response. On the other hand, three of the nine cases with HSV-1 seroconvertants also showed increasing HSV-2 gG2 antibody levels. Cross reactive low avidity IgG or IgA antibody response $^{32} 33$ to the gGl protein following HSV-1 infection may be transiently detected by the gG2 antigen.

Although gG1 and gG2 western blot assays are the gold standard for the determination of type specific HSV antibodies, ${ }^{9} 13$ the sensitivity of these assays is not superior to that of ELISA techniques based on similar antigens. ${ }^{34}{ }^{35}$ Using baculovirus gG1 and gG2 dot blot assays for comparable serial samples, reversion from HSV-1 or HSV-2 seropositive to seronegative has been described in $5 \%-12 \%$ of individuals (Pellet P, personal communication). We found a highly significant difference between the reversion rates of HSV-1 gG1 and HSV-2 gG2 antibodies. Although the general decline of antibody levels during pregnancy ${ }^{16}$ might play a role, the nature and impact of the specific 
decline of HSV-2 gG2 IgG antibody levels warrant further investigation.

Contributors: M Lehtinen was responsible for the laboratory and data analyses, participated in the study design, and writing th manuscript; M Arvaja performed the laboratory analyses and participated in writing the manuscript; P Koskela was responsible for the study logistics, participated in the study design, and writing the manuscript; $M$ Lappalainen, $T$ Vesikari, and $\mathrm{J}$ Paavonen participated in the study design and writing the manuscript.

1 Randolph A, Washington E, Prober C. Cesarean delivery for women presenting with genital herpes lesions. FAMA 1993;270:77-82.

2 Prober C, Sullender W, Yasukawa L, et al. Low risk of herpes simplex virus infection in neonates exposed to the virus at the time of a vaginal delivery to mothers with recurrent herpes simplex virus infection. $N$ Engl f Med 1987;316: $240-4$.

3 Brown Z, Benedeffi J, Ashley R, et al. Neonatal herpes simplex virus infection in relation to asymptomatic maternal plex virus infection in relation to asymptomatic maternal infection

4 Brown ZA, Selke S, Zeh J, et al. The acquisition of herpes simplex virus during pregnancy. N Engl f Med 1997;337 509-15.

5 Brown Z, Vontver L, Benedeffi J, et al. Effects on infants of a first episode of genital herpes during pregnancy. $N$ Engl Med 1987;317:1246-51

6 Whitley R, Arvin A, Prober C, et al. Predictors of morbidity and mortality in neonates with herpes simplex virus infections. N Engl F Med 1991;324:450-4.

7 Koutsky LA, Stevens CE, Holmes KK, et al. Underdiagnosis of genital herpes by current clinical and viral-isolation procedures. N Engl f Med 1992;326:1533-9.

8 Arvin AM, Hensleigh PA, Prober CG, et al. Failure of antepartum maternal cultures to predict the infant's risk of antepartum maternal cultures to predict the infant's risk of exposure to herpes

9 Ashley R, Cent A, Maggs V, et al. Inability of enzyme immunoassays to discriminate between infections with herpes simplex virus types 1 and 2. Ann Intern Med 1991;115:5206.

10 Suchankova A, Hirsch I, Kremar M, et al. Determination of herpes simplex virus type-specific antibodies by solid-phase RIA on helix pomatia lectin-purified antigens. F Infect Dis 1984;149:964-72.

11 Lee F, Coleman R, Pereira L, et al. Detection of herpes simplex virus type 2 -specific antibody with glycoprotein $\mathrm{G}$. $\mathscr{f}$ Clin Microbiol 1985;22:641-4.

12 Sullender W, Yasukawa L, Schwartz M, et al. Type-specific antibodies to herpes simplex virus type 2 (HSV-2) antibodies to herpes simplex virus type 2 (HSV-2) glycoprotein G in pregnant women, infants exposed to natal herpes. F Infect Dis 1988;157:164-71.

13 Cowan F, Johnson A, Ashley R, et al. Antibody to herpes simplex virus type 2 as serological marker of sexual lifestyle in population. BMF 1994;309:1325-9.

14 Sanchez-Martinez D, Schmid DS, Whittington W, et al. Evaluation of a test based on baculovirus-expressed glycoprotein $G$ for detection of herpes simplex virus typespecific antibodies. F Infect Dis 1991;164:1 196-9.

15 Boucher F, Yasukawa L, Kerns K, et al. Detection of antibodies to herpes simplex virus type 2 with a mammalian cell line expressing glycoprotein gG2 Clin Diagn Virol 1993;1:29-38

16 Lappalainen M, Koskela P, Koskiniemi M, et al. Toxoplasmosis acquired during pregnancy: improved serodiagnosis mosis acquired during pregnancy: improved serodiag

17 Sanchez-Martinez D, Pellett PE. Expression of HSV-1 and HSV-2 glycoprotein G in insect cells by using a novel baculovirus expression vector. Virology 1991;182:229-38.
18 Lehtinen M, Koivisto V, Lehtinen T, et al. Immunoblotting and enzyme linked immunosorbent assay analysis of serological responses in patients infected with herpes simplex virus types 1 and 2. Intervirology 1985;24:18-25.

19 Lehtinen M, Leminen A, Kuoppala T, et al. Pre- and posttreatment serum antibody responses to HPV 16 E2 and HSV-2 ICP8 proteins in women with cervical carcinoma. $f$ Med Virol 1992;37:180-6.

20 Bouwes Bavinck J, Gissmann L, Claas F, et al. Relation between skin cancer, humoral responses to human papillomaviruses and HLA class II molecules in renal transplant maviruses and HLA class II molecules in
recipients. F Immunol 1993;151:1579-86.

21 Miettinen A, Paavonen J, Jansson E, et al. Enzyme immunoassay for serum antibody to mycoplasma hominis in women with acute pelvic inflammatory disease. Sex Transm Dis 1983;10:289-93.

22 Lehtinen M, Parkkonen P, Luoto H, et al. Antipeptide IgA antibodies to a human papillomavirus type $16 \mathrm{E} 2$ derived synthetic peptide predict the natural history of cervical HPV infection. In: Monsonego J ed. Proceedings of the European Multidisciplinary Congress on Human Papillomavirus. pean Yultidisciplinary Congress on Human Papillomavirus. 509-19.

23 Nahmias A, Lee F, Beckman-Nahmias S. Seroepidemiological and sociological patterns of herpes simplex virus infection in the world. Scand F Infect Dis 1990;(suppl) 69:19-36.

24 Whitley RJ. Herpes simplex virus infections of women and their offspring:implications for a developed society. Proc Natl Acad Sci USA 1994;91:2441-7.

25 Forsgren M, Skoog E, Jeansson S, et al. Prevalence of antibodies to herpes simplex virus in pregnant women in Stockholm in 1969, 1983, and 1989: implications for STD epidemiology. Int f STD AIDS 1994;5:113-6.

26 Persson $\mathrm{K}$, Månsson $\mathrm{A}$, Jonsson $\mathrm{E}$, et al. Decline of herpes simplex virus type 2 and Chlamydia trachomatis infections from 1970 to 1993 indicated by a similar change in antibody pattern. Scand $\mathcal{F}$ Infect Dis 1995;27:195-9.

27 Johnson R, Nahmias A, Magder L, et al. A seroepidemiologic survey of the prevalence of herpes simplex virus type logic survey of the prevalence of herpes simplex virus type 2 infec.

28 Christenson B, Böttiger M, Svensson Å, et al. A 15-year surveillance study of antibodies to herpes simplex virus types 1 and 2 in a cohort of young girls. F Infect 1992;25:147-54.

29 Mertz G, Benedeffi J, Ashley R, et al. Risk factors for the sexual transmission of genital herpes. Ann Intern Med 1992;116:197-202

30 McGeoch D, Moss H, McNab D, et al. DNA sequence and genetic content of the hindIII 1 region in the short unique component of the herpes simplex virus type 2 genome: identification of the gene encoding glycoprotein $\mathrm{G}$, and evolutionary comparisons. f Gen Virol 1987;68:1938-43.

31 Ashley RL, Corey L, Dalessio J, et al. Protein-specific cervical antibody responses to primary genital herpes simplex virus type 2 infections. F Infect Dis 1994;170:20-6.

32 Stanley C, Lew A, Steward M. The measurement of antibody affinity: a comparison of five techniques utilizing a panel of monoclonal anti-DNP antibodies and the effect of high affinity antibody on the measurement of low affinity antibody. F Immunol Meth 1983;64:119-32.

33 Jones C, MacDonald R, Hosking C, et al. Estimating the relative avidity of mucosal IgA for antigen. F Immunol Meth 1987;105:111-7.

34 Ashley RL, Wu L, Pickering JW, et al. Premarket evaluation of a commercial glycoprotein G-based enzyme immunoassay for herpes simplex virus type-specific antibodies. Clin Microbiol 1998;36:294-5.

35 Groen J, van Dijk G, Niesters H, et al. Comparison of two enzyme-linked immunosorbent assays and one rapid immunoblot for the detection of herpes simplex virus type-2 specific antibodies in serum. 7 Clin Microbiol 1998; type-2 specific 